\title{
Chiral BINOL-centered dendrimers for the enantioselective Lewis acid catalyzed diethylzinc addition to aldehydes
}

\author{
Guo-Hua Liu, Qing-Hua Fan, Xi-Qiang Yang, Xiao-Min Chen \\ Laboratory of Chemical Biology, Center for Molecular Science, Institute of Chemistry, \\ The Chinese Academy of Sciences, Beijing 100080, P. R. China \\ E-mail: fanqh@infoc3.icas.ac.cn
}

Dedicated to Prof. Zhi-Tang Huang on the occasion of his $75^{\text {th }}$ birthday

(received 31 Dec 02; accepted 29 Apr 03; published on the web 08 May 03)

\begin{abstract}
Two kinds of dendritic chiral BINOL ligands have been synthesized through the condensation reaction between 2,2'-dihydroxy-1,1'-binaphthyl-3,3'-dicarboxylic acid and Fréchet-type polyether dendrons with primary and secondary amine at the focal point, respectively. These dendritic chiral BINOL ligands were found to be effective in the enantioselective addition of diethylzinc to benzaldehyde both in the presence and absence of $\mathrm{Ti}\left[\mathrm{OCH}\left(\mathrm{CH}_{3}\right)_{2}\right]_{4}$. Much different enantioselectivity was observed in both cases. In the former case, $(R)$-2 showed moderate enantioselectivity, which was much higher than that of $(R)-3$. The size/generation of the dendrimer 2 did not significantly influence the enantioselectivity. In the latter case, $(R)-3$ gave the highest enantioselectivity as compare to $(R)-\mathbf{1},(R)-\mathbf{2}$ and BINOL, which decreased on going from $\mathbf{3}-\mathbf{G}_{\mathbf{0}}$ to $\mathbf{3}-\mathbf{G}_{\mathbf{1}}$.
\end{abstract}

Keywords: Chiral dendrimer, BINOL, asymmetric catalysis, alkylation

\section{Introduction}

During the last decade, enormous progress has been obtained in the field of dendrimers research owing to their unique physical and chemical properties. ${ }^{1}$ One of the main applications of dendrimers is in catalysis. ${ }^{2-4}$ The first example of dendritic catalyst was reported by van Koten et al in $1994 .^{5}$ The properties of regular monodisperse structure and multiarm topology of dendrimers offers better control of the number, shape and structure of the active sites and of their microenvironment as compared with the heterogeneous, polydisperse polymer-supported catalysts. Such novel catalysts can be used under homogeneous condition and be readily recovered via simple supra-filtration or solvent precipitation methods. Therefore, dendrimerbased catalysts may fill the gap between homogeneous and heterogeneous catalysis and combine 
the advantages of both. Although a number of dendritic catalysts have been described, so far, relatively few reports on catalytic asymmetric catalysis employing chiral dendritic catalysts are available.

We have been interested in the core-functionized dendritic chiral catalyst for asymmetric catalysis. ${ }^{6-7}$ In the case of metal-centered dendrimers, the size of the dendritic wedges, just like enzymes, can create a well-defined microenvironment around catalytic sites and mimic the high selectivity like enzymatic reactions. ${ }^{8-9}$ Most recently, we have developed two types of chiral dendritic ligands for asymmetric catalysis through the incorporation of $\mathrm{BINAP}^{6}$ and $\mathrm{BINOL}^{7}$ into the core of the Fréchet-type dendrimers, respectively. In both cases, it was found that the size of the dendritic wedges influenced the reactivity and the enantioselectivity of the dendritic catalysts. The "dendritic effects" were probably due to the space-filling nature of the dendritic wedges near the metal center, which would alter the structure of the metal complex and thus possibly influence the reactivity of the catalyst and/or the substrate selectivity of the catalytic reaction with increasing generation of the dendrimer. For example, the dendritic BINOL ligands 1 were found to be highly effective in the enantioselective addition of diethylzinc to benzaldehyde both in the presence and in the absence of $\operatorname{Ti}\left[\mathrm{OCH}\left(\mathrm{CH}_{3}\right)_{2}\right]_{4}$, albeit gave lower enantioselectivity with the increasing generation of the dendrimer. ${ }^{7}$ This indicated that the microenvironment of the catalytic sites of the dendritic catalysts is very important for their effectiveness in steric control. Several types of chiral dendritic BINOL ligands bearing dendrimer wedges were recently described, however, so far, no precedents exist concerning the modification of the microenvironment of the catalytic sites of the dendritic catalysts through systematically adjusting both the linking groups and the generations of the dendrimer wedges. ${ }^{7} 10-12$

In this paper, we designed and synthesized several chiral dendritic BINOL ligands ( 2 and 3 ) through the condensation reaction between BINOL derivative and Fréchet-type polyether dendrons. These dendrimer ligands were applied to the enantioselective addition of diethylzinc to aldehydes for comparing their performance. Rather different reactivity and enantioselectivity have been achieved through adjusting the microenvironmental structure of the dendritic catalysts via changing the linkers and generations of the dendritic wedges.

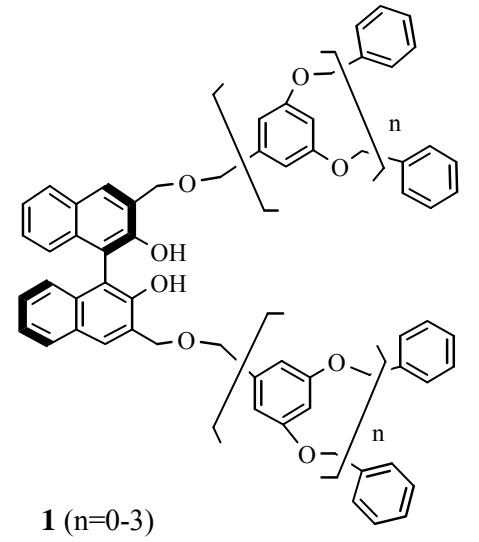

$1(n=0-3)$

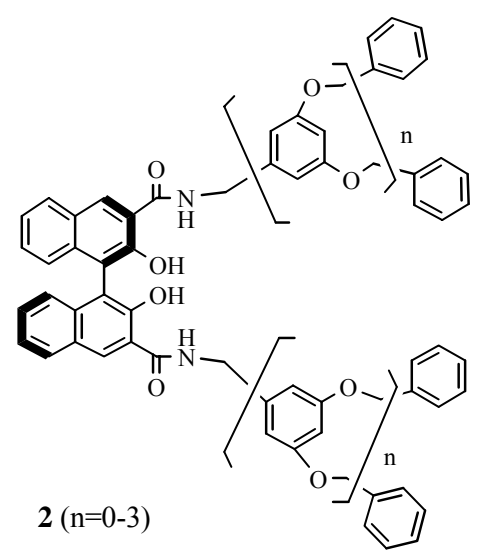

$2(n=0-3)$

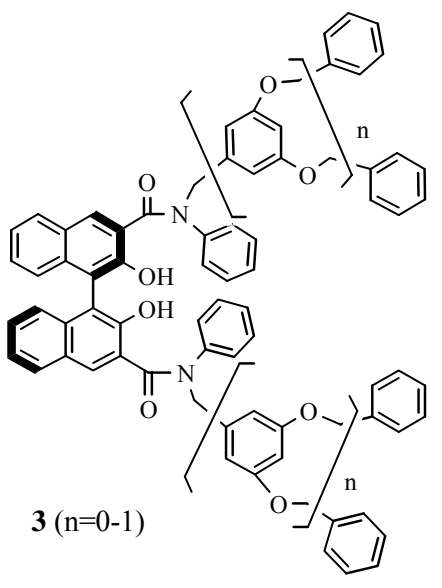




\section{Results and Discussion}

Synthesis of chiral dendritic BINOL ligands $\mathbf{2}\left(\mathbf{2}-\mathbf{G}_{\mathbf{0}} \sim \mathbf{2}-\mathbf{G}_{3}\right)$ and $\mathbf{3}\left(\mathbf{3}-\mathbf{G}_{\mathbf{0}} \sim \mathbf{3}-\mathbf{G}_{\mathbf{1}}\right)$. The commercially available $(R)$-BINOL was chosen as model ligand for this study due to its very extensive applications in asymmetric catalysis. ${ }^{13}$ The 3,3'-positions on the naphthyl backbone of BINOL were chosen for the attachment of dendritic wedges due to the proximity of the dendritic wedges to the catalytic center, which may provide a potential opportunity to study the influence of the shape and architecture of the dendritic wedges on the chiral microenvironment built around the catalytic active site through systematically adjusting the generation of the dendrimer. The synthetic route is outlined in Scheme 1. Firstly, the BINOL derivative, 2, 2'-dihydroxy -1, 1'binaphthyl-3, 3'-dicarboxylic acid 4, was synthesized according to the procedure reported by Kitajima et al. ${ }^{14}$ The hydroxyl group of BINOL was protected with the methoxyl methyl (MOM) group. The MOM-protected BINOL was then lithiated by n-BuLi followed by carboxylation and deprotection reactions to give 4 with overall 54\% yield.

We chose Fréchet-type polyether dendrimer as supports due to their inertness to catalytic reaction. Two kinds of polyether dendrons with primary and secondary amine groups located at the focal point were synthesized by the convergent-group approach. Fréchet-type dendrons with bromide at the focal point were prepared according to the procedure introduced by Hawker and Fréchet. ${ }^{15}$ The resulting bromides were converted into their corresponding amines by using the method reported by Vogtle et al. ${ }^{16}$ Classical Gabriel synthesis, introduction of the phthalimide followed by deprotection of the amine using hydrazine, resulted in dendritic amines 5 . The first generation of secondary amine dendron 7 was synthesized through the alkylation reaction between phenylamine and the Fréchet-type dendritic bromide 6 in the presence of triethylamine in high reaction yield.

Finally, the chiral dendritic BINOL ligands $\mathbf{2}-\mathbf{G}_{\mathbf{1}} \sim \mathbf{2}-\mathbf{G}_{\mathbf{3}}$ and $\mathbf{3}-\mathbf{G}_{\mathbf{1}}$ were successfully prepared through the coupling of 4 with the corresponding dendrons 5 and 7 , respectively. 4 was first chlorinated with $\mathrm{SOCl}_{2}$ followed by reactions with $\mathbf{5}$ and $\mathbf{7}$ in the presence of triethylamine to give $\mathbf{2}-\mathbf{G}_{\mathbf{1}} \sim \mathbf{2}-\mathbf{G}_{\mathbf{3}}$ and $\mathbf{3}-\mathbf{G}_{\mathbf{1}}$, respectively, in moderate yields. For comparison, the corresponding zero generation compounds $\mathbf{2}-\mathbf{G}_{\mathbf{0}}$ and $\mathbf{3}-\mathbf{G}_{\mathbf{0}}$ were also synthesized with the same method.

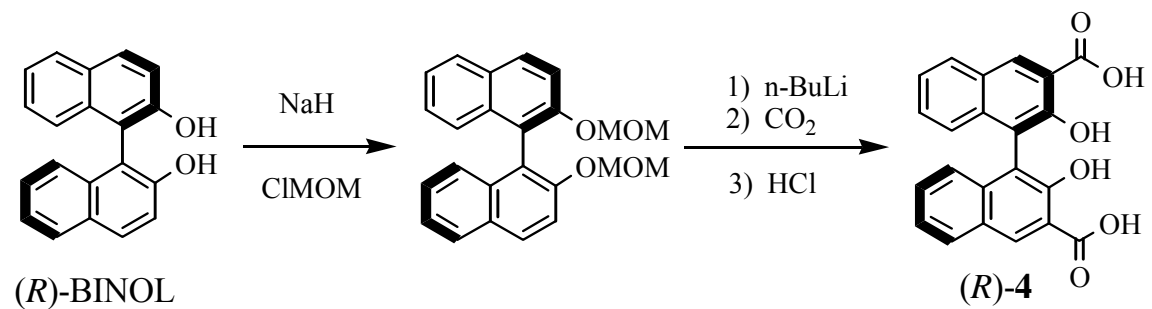



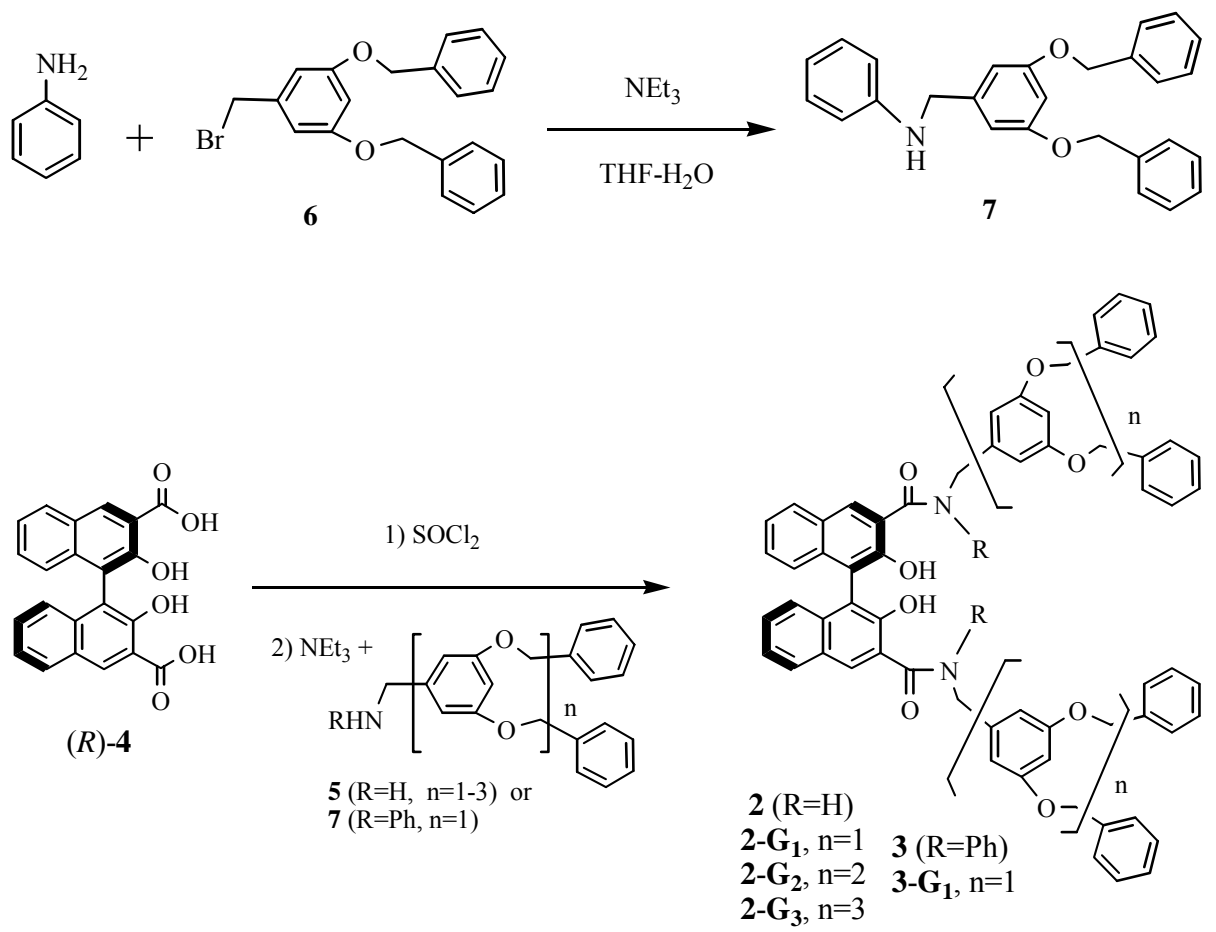

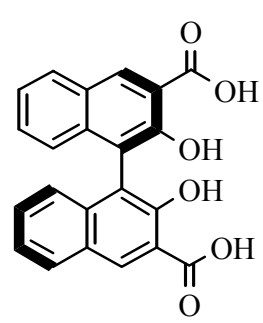

$(R)-4$
1) $\mathrm{SOCl}_{2}$

2) $\mathrm{NEt}_{3}+$ benzylamine or $\mathrm{NEt}_{3}+$ phenylbenzylamine

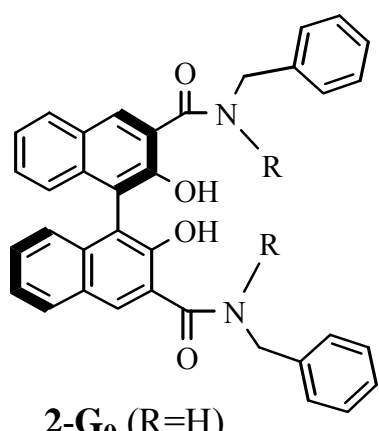

$2-\mathrm{G}_{0}(\mathrm{R}=\mathrm{H})$

\section{Scheme 1}

All of these dendritic BINOL ligands were characterized by IR, NMR, MS. All results are in full agreement with the proposed structures. The well-resolved ${ }^{1} \mathrm{H}$ NMR spectra indicate that these dendritic BINOLs maintain a $\mathrm{C}_{2}$ symmetry in solution. The IR spectra give a strong absorption at about $1655 \mathrm{~cm}^{-1}$, which indicates the existence of the carbonyl group. Some of the characterization data are summarized in Table 1. The MALDI TOF MS spectra of $2-\mathrm{G}_{1}, 2-\mathrm{G}_{2}$ and $2-\mathrm{G}_{3}$ showed the ions as $999.7\left([\mathrm{M}+\mathrm{Na}]^{+}\right), 1849.4\left([\mathrm{M}+\mathrm{Na}]^{+}\right)$and $3545.7\left([\mathrm{M}+\mathrm{Na}]^{+}\right)$respectively, which clearly demonstrated the formation of monodispersed dendritic BINOLs. The optical rotation and molar rotation data are also collected in Table 1 . The specific optical rotation $[\alpha]^{20}{ }_{D}$ decreased with the increase of the dendrimer generation. However, the molar rotation was almost identical regardless of the generation, which showed that the dendritic wedges attached to the 
binaphthyl core did not lead to major chiral amplification.

Table 1. Characterization of chiral dendritic ligands

\begin{tabular}{cccccc}
\hline Compd & Yields, \% & $\begin{array}{c}\text { Calcd } \\
\text { mass }\end{array}$ & $\begin{array}{c}\text { Mass found } \\
{\left[\mathrm{M}+\mathrm{Na}^{+}\right.}\end{array}$ & {$[\alpha]^{20}$} & $\begin{array}{c}\text { Molar } \\
\text { rotation }\end{array}$ \\
\hline$(R)-2-\mathrm{G}_{0}$ & 69.1 & 552.6 & 575.9 & $+102\left(\mathrm{c}=1.0, \mathrm{CHCl}_{3}\right)$ & 563.0 \\
$(R)-2-\mathrm{G}_{1}$ & 60.0 & 976.4 & 999.7 & $+52.0\left(\mathrm{c}=1.0, \mathrm{CHCl}_{3}\right)$ & 508.1 \\
$(R)-2-\mathrm{G}_{2}$ & 75.0 & 1824.7 & 1849.4 & $+22.0\left(\mathrm{c}=1.0, \mathrm{CHCl}_{3}\right)$ & 401.8 \\
$(R)-2-\mathrm{G}_{3}$ & 72.0 & 3521.4 & 3545.7 & $+10.0\left(\mathrm{c}=1.0, \mathrm{CHCl}_{3}\right)$ & 352.4 \\
$(R)-3-\mathrm{G}_{0}$ & 79.8 & 704.2 & 726.9 & $+90.0\left(\mathrm{c}=1.0, \mathrm{CH}_{2} \mathrm{Cl}_{2}\right)$ & 633.6 \\
$(R)-3-\mathrm{G}_{1}$ & 74.5 & 1128.4 & 1151.0 & $+56.0\left(\mathrm{c}=1.0, \mathrm{CH}_{2} \mathrm{Cl}_{2}\right)$ & 631.7 \\
\hline
\end{tabular}

Asymmetric induction of the dendritic BINOL ligands in the enantioselective addition of $\mathrm{ZnEt}_{2}$ to benzaldehyde in the presence or in the absence of Ti[OCH($\left.\left(\mathrm{CH}_{3}\right)_{2}\right]_{4}$. In recent years, the titanium complexes of BINOL were reported to be effective catalysts for the asymmetric addition of diethylzinc to aldehydes by Zhang and $\mathrm{Chan}^{17}$ and Mori and Nakai ${ }^{18}$. Most recently, we also applied the chiral dendritic BINOL ligand (1) to the addition of diethylzinc to benzaldehyde. ${ }^{7}$ In order to establish the relationship between the linker or the size/generation of the dendrimer and its catalytic properties, these dendritic chiral BINOL ligands were employed in the titanium Lewis acid catalyzed enantioselective addition of diethylzinc to aldehydes (Scheme 2).

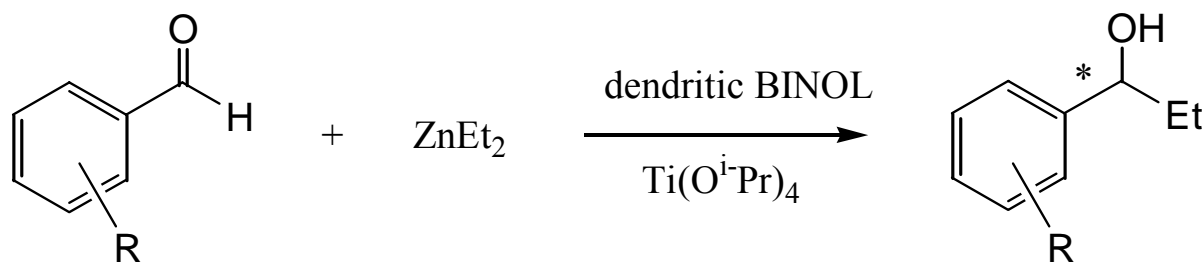

\section{Scheme 2}

According to our previous study, we chosed toluene as reaction solvent, and an aldehyde: ligand: $\operatorname{Ti}\left(\mathrm{O}^{\mathrm{i}} \mathrm{Pr}\right)_{4}: \mathrm{ZnEt}_{2}$ molar ratio of 1.0:0.2:0.8:3 as the standard reaction condition. All these dendritic chiral BINOL ligands were found to be highly effective and chemoselective in the titanium-catalyzed addition of diethylzinc to benzaldehyde, which was converted to 1-phenyl-1propanol in more than $98 \%$ yield and with no byproduct. As shown in Table 2, when using benzaldehyde as substrate, the size of the dendritic wedges of 2 did not significantly influence the enantioselectivity of the catalyst (entries 2-5). These results are much different from those of dendritic BINOL ligands 1 , in which the enantioselectivity of the catalysts decreased upon going from the zero generation to the third generation dendrimer (data in the bracket of entries 2-5). In order to further demonstrate the size/generation effect of the dendritic BINOL ligand 2, another two aldehydes were used as substrates. When using ortho-chlorinated benzaldehyde as substrate, 
similar enantioselectivities were obtained as compared with those of benzaldehyde (entries 7-9). In the case of meta-chlorinated benzaldehyde, slight decrease of ee was observed upon going from the first generation to the third generation dendrimer (entries 10-12).

Table 2. Asymmetric addition of diethylzinc to benzaldehyde catalyzed by $(R)$-BINOL and dendritic BINOL ligands in the presence of Ti[OCH( $\left.\left(\mathrm{CH}_{3}\right)_{2}\right]_{4}{ }^{\mathrm{a}}$

\begin{tabular}{ccccc}
\hline Entry & Ligand & Substrate & Conv. $(\%)^{\mathrm{b}}$ & e.e (\%) \\
\hline 1 & $(R)-\mathrm{BINOL}$ & PhCHO & 98.4 & 85.1 \\
2 & $(R)-2-\mathrm{G}_{0}$ & PhCHO & 96.1 & $66.4(84.1)^{\mathrm{c}}$ \\
3 & $(R)-2-\mathrm{G}_{1}$ & PhCHO & 97.2 & $71.7(73.7)^{\mathrm{c}}$ \\
4 & $(R)-2-\mathrm{G}_{2}$ & PhCHO & 99.4 & $65.8(53.8)^{\mathrm{c}}$ \\
5 & $(R)-2-\mathrm{G}_{3}$ & PhCHO & $>99$ & $70.1(52.2)^{\mathrm{c}}$ \\
$6^{\mathrm{d}}$ & $(R)-2-\mathrm{G}_{3}$ & PhCHO & $>99$ & 69.7 \\
7 & $(R)-2-\mathrm{G}_{1}$ & 2-Cl-PhCHO & $>99$ & 67.6 \\
8 & $(R)-2-\mathrm{G}_{2}$ & 2-Cl-PhCHO & $>99$ & 69.2 \\
9 & $(R)-2-\mathrm{G}_{3}$ & 2-Cl-PhCHO & $>99$ & 72.8 \\
10 & $(R)-2-\mathrm{G}_{1}$ & 3-Cl-PhCHO & $>99$ & 51.9 \\
11 & $(R)-2-\mathrm{G}_{2}$ & 3-Cl-PhCHO & $>99$ & 46.5 \\
12 & $(R)-2-\mathrm{G}_{3}$ & 3-Cl-PhCHO & 98 & 45.7 \\
13 & $(R)-3-\mathrm{G}_{0}$ & PhCHO & $>99$ & 4.3 \\
\hline
\end{tabular}

${ }^{\mathrm{a}}$ Benzaldehyde $:$ ligand $: \mathrm{ZnEt}_{2}=1.0: 0.2: 3$ (molar ratio), reaction temperature $=0{ }^{\circ} \mathrm{C}$; solvent $=$ toluene; reaction time $=7 \mathrm{hr}$.

${ }^{\mathrm{b}}$ Determined by chiral GLC analyses. The absolute configuration of product is $R$.

${ }^{\mathrm{c}}$ Data in bracket, see: Ref. 7.

${ }^{\mathrm{d}}$ Recycle chiral dendritic BINOL ligand was used.

According to our pevious $\mathrm{study}^{7}$, the oxygen on the linker of the dendritic BINOL might possibly coordinate to titanium and/or zinc atoms which resulted in much different catalytic properties as compare to BINOL. In this study, the amide linkers also significantly influenced the enantioselectivity. In comparing with BINOL and the zero generation of dendrimer 1, titanium complex of $2-\mathrm{G}_{0}$ gave lower ee than 1 (entries 1 and 2). When using $3-\mathrm{G}_{0}$ as ligands, high conversion, albeit much lower ee was observed than 1 (entry 13).

The importance of the attachment of dendritic wedges, on the other hand, is the easy and reliable separation of the chiral BINOL ligands due to their different solubilities in various organic solvents. For example, upon completion of the reaction, chiral BINOL ligands were quantitatively precipitated by the addition of methanol and recovered via filtration. The recovered ligands showed the same enantioselectivity and reactivity (entry 6).

We have also studied the use of these dendritic BINOL ligands in catalyzing the enantioselective reaction of benzaldehyde with diethylzinc in the absence of Ti[OCH$\left.\left(\mathrm{CH}_{3}\right)_{2}\right]_{4}$. It was found that these chiral dendritic ligands performed very differently from the BINOL and 1. 
$(R)$-2 gave high conversion, albeit much lower enantioselectivity as compared to 1 (entries 1 and $2)$. In contrast to $(R)-1$ and $(R)-2,(R)-3$ offered the highest enantioselectivity in the asymmetric addition of diethylzinc to benzaldehyde in the absence of Ti[OCH$\left.\left(\mathrm{CH}_{3}\right)_{2}\right]_{4}$ (entries 3 and 4). This was possibly due to the formation of better catalyst through the coordination of nitrogen on the linker to zinc atom, which was consistent with the findings of Kitajima et al. ${ }^{14}$ On the other hand, the enantioselectivity decreased upon going from $3-\mathrm{G}_{0}$ to $3-\mathrm{G}_{1}$ (entries 3 and 4 ).

Table 3. Asymmetric addition of diethylzinc to benzaldehyde catalyzed by $(R)$-BINOL and dendritic BINOL ligands in the absence of Ti[OCH( $\left.\left(\mathrm{CH}_{3}\right)_{2}\right]_{4}{ }^{\mathrm{a}}$

\begin{tabular}{cccc}
\hline Entry & ligand & Conv. $(\%)^{\mathrm{b}}$ & e.e $(\%)^{\mathrm{b}}$ \\
\hline 1 & $(R)-2-\mathrm{G}_{0}$ & 96.1 & $8.6(66.0)^{\mathrm{c}}$ \\
2 & $(R)-2-\mathrm{G}_{1}$ & 97.2 & $7.7(61.9)^{\mathrm{c}}$ \\
3 & $(R)-3-\mathrm{G}_{0}$ & $>99$ & 93.3 \\
4 & $(R)-3-\mathrm{G}_{1}$ & $>99$ & 89.6 \\
\hline
\end{tabular}

a Benzaldehyde : ligand : $\mathrm{ZnEt}_{2}=1.0: 0.2: 3$ (molar ratio), reaction temperature $=0{ }^{\circ} \mathrm{C}$; solvent, toluene; reaction time $=7 \mathrm{hr}$.

${ }^{\mathrm{b}}$ Determined by chiral GLC analyses. The absolute configuration of product is $R$.

${ }^{\mathrm{c}}$ Data in bracket, see: Ref. 7.

In summary, two kinds of dendritic chiral BINOL ligands have been synthesized through the condensation reaction between 2,2'-dihydroxy-1,1'-binaphthyl-3,3'-dicarboxylic acid and Fréchet-type polyether dendrons with primary and secondary amine at the focal point, respectively. These dendritic chiral BINOL ligands were found to be effective in the enantioselective addition of diethylzinc to benzaldehyde both in the presence and absence of $\mathrm{Ti}\left[\mathrm{OCH}\left(\mathrm{CH}_{3}\right)_{2}\right]_{4}$. Much different enantioselectivity was observed in both cases. In the former case, $(R)-2$ showed moderate enantioselectivity, which was much higher than that of $(R)-3$. The size/generation of the dendrimer 2 did not significantly influence the enantioselectivity. In the latter case, $(R)-3$ gave the highest enantioselectivity as compared with $(R)-1,(R)-2$ and BINOL, which decreased on going from $3-\mathrm{G}_{0}$ to $3-\mathrm{G}_{1}$.

\section{Experimental Section}

General Procedures. IR was recorded on a Bruker IFS 25 spectrophotometer. The ${ }^{1} \mathrm{H}-\mathrm{NMR}$ was recorded on a Bruker DM 300 spectrometer in $\mathrm{CDCl}_{3}$ with TMS as internal standard. MALDITOF mass spectra were obtained on an Instrum III spectrometer with $\alpha$-cyano-4hydroxycinnamic acid (CCA) as a matrix. Elemental analysis was performed with a Carlo Erba 1106 Elemental Analyzer. Optical rotations were measured with AA-10R automatic polarimeter. The e.e. values were determined by GLC using a Supelco $\beta$-Dex 120 chiral column (30 m x 0.25 
$\mathrm{mm}$ (i.d.), $0.25 \mu \mathrm{m}$ film).

Materials. All experiments, which are sensitive to moisture or air, were carried out under a nitrogen atmosphere using standard Schlenk techniques. Commercial reagents were used as received without further purification unless otherwise noted. Toluene and THF were distilled from sodium benzophenone ketyl, and dichloromethane from calcium hydride. Benzaldehyde was distilled from calcium hydride before use. Compounds $(R)-4$ and 5 were synthesized according to the reported procedures. ${ }^{14-16}$

Synthesis of dendron (7). Under a nitrogen atmosphere, to a stirred solution of 6 (1.0 g, 2.6 $\mathrm{mmol})$ in THF $(10 \mathrm{~mL})$ and $0.37 \mathrm{ml}$ triethylamine was slowly added $0.24 \mathrm{ml}$ of phenylamine and the mixture was refluxed for $4 \mathrm{~h}$. The reaction mixture was then acidified with $5 \% \mathrm{HCl}$ and extracted with $\mathrm{CH}_{2} \mathrm{Cl}_{2}$ three times. The combined organic layers were washed with $10 \% \mathrm{Na}_{2} \mathrm{CO}_{3}$ solution and brine, dried over $\mathrm{Na}_{2} \mathrm{SO}_{4}$. After removing the solvent the residue was further purified by column chromatography on silica gel (hexane : ethyl acetate $=4: 1)$ to give $7(0.98 \mathrm{~g}$, $95 \%$ yield) as a white solid. IR (KBr): $3428,1593,1162,1057,1027 \mathrm{~cm}^{-1} ;{ }^{1} \mathrm{H}$ NMR $\left(\mathrm{CDCl}_{3}\right): \delta$ 7.44-7.33 (m, 10H, Ar-H), 7.19 (t, J = 7.92 Hz, 2H, Ar-H), 6.77-6.50 (m, 6H, Ar-H), 4.29 (s, 2H, Ar- $\left.\mathrm{CH}_{2}\right), 4.06$ (s, H, N-H); MS (EI): m/z(\%): 396(2.8), 395(8.6), 302(4.0), 181(3.6), 106(5.2), 105(5.7), 91(100), 77(8.1), 65(8.8).

\section{A typical procedure for synthesis of chiral dendritic BINOL ligands}

$(\boldsymbol{R})-\mathbf{2}-\mathbf{G}_{0}{ }^{19}$ Under a nitrogen atmosphere, a stirred solution of $(R)-40.1 \mathrm{~g}(0.27 \mathrm{mmol})$ in $\mathrm{SOCl}_{2}$ $(5 \mathrm{~mL})$ was refluxed for $4 \mathrm{~h}$. After removal $\mathrm{SOCl}_{2}$, to the resulting acid chloride was added a solution of benzyl amine $(1 \mathrm{ml})$ in $5 \mathrm{ml} \mathrm{CH}_{2} \mathrm{Cl}_{2}$ at $0{ }^{\circ} \mathrm{C}$. The solution was stirred for $1 \mathrm{~h}$ at $0{ }^{\circ} \mathrm{C}$. The reaction mixture was then acidified to $\mathrm{pH}=2$ with $5 \% \mathrm{HCl}$ and extracted with $\mathrm{CH}_{2} \mathrm{Cl}_{2}$ three times. The combined organic layer was washed with $10 \% \mathrm{Na}_{2} \mathrm{CO}_{3}$ solution and brine, dried over $\mathrm{Na}_{2} \mathrm{SO}_{4}$. After removing the solvent the residue was further purified by column chromatography on silica gel (hexane : ethyl acetate $=2: 1, \mathrm{v} / \mathrm{v})$ to give $(R)-2-\mathbf{G}_{0}$ as a yellow crystals $(69 \%$ yield). $[\alpha]_{D}^{20}=+102\left(\mathrm{c} 1, \mathrm{CHCl}_{3}\right)$; IR (KBr): 3341, 1647, 1581,1452, 1230, $1080 \mathrm{~cm}^{-1} ;{ }^{1} \mathrm{H}$ NMR $\left(\mathrm{CDCl}_{3}\right): \delta 12.2(\mathrm{~s}, 2 \mathrm{H}), 8.08$ (s, 2H, BINOL-H), 7.82-7.17 (m, 20H, Ar-H), $4.73(\mathrm{~s}, 4 \mathrm{H}$, $\left.\mathrm{Ph}-\mathrm{CH}_{2}\right)$.

$(\boldsymbol{R})-\mathbf{2}-\mathbf{G}_{1}$. According to the above procedure, the resulting residue was purified by column chromatography on silica gel (hexane : ethyl acetate $=1: 1$ ) to give $(R)-\mathbf{2}-\mathbf{G}_{\mathbf{1}}$ as a yellow foam $(60 \%$ yield $) \cdot[\alpha]^{20}{ }_{\mathrm{D}}=+52\left(\mathrm{c} 1, \mathrm{CHCl}_{3}\right)$; IR $(\mathrm{KBr}): 3372,3080,2863,1651,1595,1532,1452$, 1296, 1262, 1152, 1028, 802, 738 $\mathrm{cm}^{-1} ;{ }^{1} \mathrm{H}$ NMR $\left(\mathrm{CDCl}_{3}\right): \delta 11.9$ (s, 2H), 8.07 (s, 2H, BINOL-H), 7.68 (d, J=7.7 Hz, 2H, BINOL-H), 7.39-7.21 (m, 26H, Ar-H), 7.09 (d, J=8.04 Hz, 2H, BINOLH), 6.61-6.55 (m, 6H, Ar-H), 4.99 (s, 8H, Ph- $\left.\mathrm{CH}_{2}\right), 4.60$ (dd, $\mathrm{J}_{1}=5.3 \mathrm{~Hz}, \mathrm{~J}_{2}=14.3 \mathrm{~Hz}, 2 \mathrm{H}, \mathrm{Ph}-$ $\left.\mathrm{CH}_{2}\right), 4.52\left(\mathrm{dd}, \mathrm{J}_{1}=5.3 \mathrm{~Hz}, \mathrm{~J}_{2}=14.2 \mathrm{~Hz}, 2 \mathrm{H}, \mathrm{Ph}-\mathrm{CH}_{2}\right)$; MALDI-TOF-MS: m/z: $999.69[\mathrm{M}+\mathrm{Na}]^{+}$. $(\boldsymbol{R})-\mathbf{2}-\mathbf{G}_{2}$. According to the above procedure, the resulting residue was purified by column chromatography on silica gel (hexane : $\left.\mathrm{CH}_{2} \mathrm{Cl}_{2}=1: 4\right)$ to give $(R)-\mathbf{2}-\mathbf{G}_{2}$ as a yellow foam $(75 \%$ yield). $[\alpha]^{20}{ }_{\mathrm{D}}=+22$ (c 1, $\mathrm{CHCl}_{3}$ ); IR (KBr): 3356, 3033, 2873, 1650, 1595, 1529, 1451, 1295 , 1152, 1053, 831, $737 \mathrm{~cm}^{-1} ;{ }^{1} \mathrm{H}$ NMR $\left(\mathrm{CDCl}_{3}\right): \delta 12.1$ (s, 2H), 8.05 (s, 2H, BINOL-H), $7.63(\mathrm{~d}$, $\mathrm{J}=7.8 \mathrm{~Hz}, 2 \mathrm{H}$, BINOL-H), 7.40-7.29 (m, 40H, Ar-H), 7.22-7.09 (m, 8H, Ar-H), 6.69-6.58 (m, 
18H, Ar-H), 5.01-4.92 (m, 24H, Ph-CH CH $_{2} 4.53-4.49$ (dd, J $\left.=5.3 \mathrm{~Hz}, \mathrm{~J}_{2}=14.3 \mathrm{~Hz}, 2 \mathrm{H}, \mathrm{Ph}-\mathrm{CH}_{2}\right)$, 4.77-4.70 (dd, $\mathrm{J}_{1}=5.3 \mathrm{~Hz}, \mathrm{~J}_{2}=14.3 \mathrm{~Hz}, 2 \mathrm{H}, \mathrm{Ph}-\mathrm{CH}_{2}$ ); MALDI-TOF-MS: m/z: $1849.36[\mathrm{M}+\mathrm{Na}]^{+}$. (R)-2-G $\mathbf{G}_{3}$. According to the above procedure, the resulting residue was purified by column chromatography on silica gel (hexane : $\left.\mathrm{CH}_{2} \mathrm{Cl}_{2}=1: 5\right)$ to give $(R)-\mathbf{2}-\mathbf{G}_{3}$ as a yellow foam (72\% yield). $[\alpha]^{20}{ }_{\mathrm{D}}=+10\left(\mathrm{c} 1, \mathrm{CHCl}_{3}\right.$ ); IR (KBr): 3380, 3031, 2870, $17261596,1448,1297,1151$, 1044, 829, 738 $\mathrm{cm}^{-1}$; ${ }^{1} \mathrm{H}$ NMR $\left(\mathrm{CDCl}_{3}\right): \delta 12.0(\mathrm{~s}, 2 \mathrm{H}), 8.05(\mathrm{~s}, 2 \mathrm{H}), 7.68(\mathrm{~s}, 2 \mathrm{H}, \mathrm{BINOL}-\mathrm{H})$, 7.43-7.10 (m, 88H, Ar-H), 6.70-6.52 (m, 42H, Ar-H), 5.07, 4.99, 4.95 (s, 56H, Ph-CH $), 4.60$ (dd, $\left.\mathrm{J}_{1}=5.4 \mathrm{~Hz}, \mathrm{~J}_{2}=14.4 \mathrm{~Hz}, 2 \mathrm{H}, \mathrm{Ph}-\mathrm{CH}_{2}\right), 4.48\left(\mathrm{dd}, \mathrm{J}_{1}=5.4 \mathrm{~Hz}, \mathrm{~J}_{2}=14.4 \mathrm{~Hz}, 2 \mathrm{H}, \mathrm{Ph}-\mathrm{CH}_{2}\right)$; MALDITOF-MS: $\mathrm{m} / \mathrm{z}: 3545.65[\mathrm{M}+\mathrm{Na}]^{+}$.

$(\boldsymbol{R})-\mathbf{3}-\mathbf{G}_{\mathbf{0}}$. According to the above procedure, the resulting residue was purified by column chromatography on silica gel (hexane : ethyl acetate $=2: 1)$ to give $(R)-\mathbf{3}-\mathbf{G}_{\mathbf{0}}$ as a yellow foam (80\% yield). $[\alpha]^{20}{ }_{\mathrm{D}}=+90.0\left(\mathrm{c} 1, \mathrm{CH}_{2} \mathrm{Cl}_{2}\right)$; IR $(\mathrm{KBr}): 3513,1733,1638,1205 \mathrm{~cm}^{-1}$; ${ }^{1} \mathrm{H}$ NMR $\left(\mathrm{CDCl}_{3}\right): \delta 9.13(\mathrm{~s}, 2 \mathrm{H}, \mathrm{BINOL}-\mathrm{OH}), 7.58$ (s, 2H, BINOL-H), 7.37-6.88 (m, 28H, Ar-H), $5.22(\mathrm{~s}$, 4H, Ar- $\left.\mathrm{CH}_{2}\right)$; MALDI-TOF-MS: $\mathrm{m} / \mathrm{z}: \quad 726.9[\mathrm{M}+\mathrm{Na}]^{+}$; Anal. Calcd. for $\mathrm{C}_{48} \mathrm{H}_{38} \mathrm{~N}_{2} \mathrm{O}_{4} . \mathrm{CH}_{3} \mathrm{COOC}_{2} \mathrm{H}_{5}$ : C, 78.77; H, 5.59; N, 3.53. Found: C, 79.20; H, 5.44; N, 3.52.

$(\boldsymbol{R})-\mathbf{3}-\mathbf{G}_{\mathbf{1}}$. According to the above procedure, the resulting residue was purified by column chromatography on silica gel (hexane : ethyl acetate $=3: 1)$ to give $(R)-\mathbf{3}-\mathbf{G}_{\mathbf{1}}$ as a yellow foam (75\% yield). $[\alpha]^{20}{ }_{\mathrm{D}}=+56.0$ (c 1, $\mathrm{CH}_{2} \mathrm{Cl}_{2}$ ); IR (KBr): 3512, 1732, 1637, 1593, 1205, $1149 \mathrm{~cm}^{-1}$; ${ }^{1} \mathrm{H}$ NMR $\left(\mathrm{CDCl}_{3}\right): \delta 9.20$ (s, 2H, BINOL-OH), 7.54 (s, 2H, BINOL-H), 7.43-6.87 (m, 38H, Ar$\mathrm{H}), 6.58(\mathrm{~s}, 4 \mathrm{H}, \mathrm{Ar}-\mathrm{H}) ; 6.53(\mathrm{~s}, 2 \mathrm{H}, \mathrm{Ar}-\mathrm{H}) ; 5.11$ (s, 4H, Ar-CH 2$) ; 5.00$ (s, 8H, Ar-CH $)$; MALDITOF-MS: m/z: $1151.0[\mathrm{M}+\mathrm{Na}]^{+}$; Anal. Calcd. for $\mathrm{C}_{76} \mathrm{H}_{60} \mathrm{~N}_{2} \mathrm{O}_{8} .0 .5 \mathrm{CH}_{3} \mathrm{COOC}_{2} \mathrm{H}_{5}: \mathrm{C}, 79.84 ; \mathrm{H}$, 5.50; N, 2.39. Found: C, 79.74; H, 5.43; N, 3.52.

\section{General procedure for asymmetric addition of diethylzinc to benzaldehyde}

Under nitrogen, $\mathrm{Ti}\left[\mathrm{OCH}\left(\mathrm{CH}_{3}\right)_{2}\right]_{4}(34 \mu \mathrm{L}, 0.10 \mathrm{mmol})$ was added to a solution of $(R)-\mathbf{2}-\mathbf{G}_{\mathbf{0}}(13.8$ $\mathrm{mg}, 0.025 \mathrm{mmol}$ ) in $1 \mathrm{~mL}$ of toluene at room temperature and the mixture was stirred at ambient temperature for $10 \mathrm{~min}$ followed by the addition of diethylzinc $(1.0 \mathrm{M}, 0.375 \mathrm{~mL})$ in hexane with continued stirring for $10 \mathrm{~min}$. Benzaldehyde $(13 \mu \mathrm{L}, 0.125 \mathrm{mmol})$ was added with microsyringe at $0{ }^{\circ} \mathrm{C}$ and the mixture was allowed to stir at $0{ }^{\circ} \mathrm{C}$ for a given time. The reaction was quenched with $2.0 \mathrm{~mL}$ of $1.0 \mathrm{~N}$ hydrochloric acid solution, the mixture was then filtered through a short pad of Celite to remove the insoluble material and the filtrate was extracted with $2 \times 1.0 \mathrm{~mL}$ of ethyl acetate. The combined organic layers were dried over $\mathrm{Na}_{2} \mathrm{SO}_{4}$ and concentrated to solvent free. The residue was purified by column chromatography on silica gel affording 1-phenyl-1propanol as a colorless liquid. The conversion and enantioselectivity of the product were determined by GLC using a Supelco $\beta$-Dex 120 chiral column (30 m x $0.25 \mathrm{~mm}$ (i.d.), $0.25 \mathrm{~m}$ film) and absolute configuration was based on the comparison with the GLC trace of known 1phenyl-1-propanol.

\section{Acknowledgements}


We are grateful to National Natural Science Foundation of China and The Chinese Academy of Sciences for financial support.

\section{References}

1. Newkome, G., Ed. In Advances in Dendritic Macromolecules; JAI: Greenwich, CT, 1999; vol. 4, pp 1-201.

2. Astruc, D.; Chardac, F. Chem. Rev. 2001, 101, 2991.

3. van Heerbeek, R.; Kamer, P. C. J.; van Leeuwen, P. W. N. M.; Reek, J. N. H. Chem. Rev. 2002, 102, 3717.

4. Fan, Q. H.; Li, Y. M.; Chan, A. S. C. Chem. Rev. 2002, 102, 3385.

5. Knapen, J. W. J.; van der Made, A. W.; de Wilde, J. C.; van Leeuwen, P. W. N. M.; Wijkens, P.; Grove, D. M.; van Koten, G. Nature 1994, 372, 659.

6. Fan, Q. H.; Chen, Y. M.; Chen, X. M.; Jiang, D. Z.; Xi, F.; Chan, A. S. C. Chem. Commun. 2000, 789.

7. Fan, Q. H.; Liu, G. H.; Chen, X. M.; Deng, G. J.; Chan, A. S. C. Tetrahedron: Asymmetry 2001, 12, 1559.

8. Brunner, H. J. Organomet. Chem. 1995, 500, 39.

9. Mak, C. C.; Chow. H. Macromolecules 1997, 30, 1228.

10. Yamago, S.; Furukawa, M.; Azuma, A.; Yoshida, J. Tetrahedron Lett. 1998, 39, 3783.

11. Hu, Q. S.; Pugh, V.; Sabat, M.; Pu, L. J. Org. Chem. 1999, 64, 7528.

12. Seller, H.; Faber, C.; Rheiner, P. B.; Seebach, D. Chem. Eur. J. 1999, 5, 3692.

13. $\mathrm{Pu}, \mathrm{L}$. Chem. Rev. 1998, 98, 2405.

14. Kitajima, H.; Ito, K.; Aoki, Y.; Katsuki, T. Bull. Chem. Soc. Jpn. 1997, 70, 207.

15. Hawker, C. J.; Fréchet, J. M. J. J. Am. Chem. Soc. 1990, 112, 7638.

16. Vogtle, F.; Plevoets, M.; Nachtsheim, G.; Worsdorfer, U. J. Prakt. Chem. 1998, 340, 112.

17. Zhang, F. Y.; Chan, A. S. C. Tetrahedron: Asymmetry 1997, 8, 585.

18. Mori, M.; Nakai, T. Tetrahedron Lett. 1997, 38, 6233.

19. Yang, X. W.; Sheng, J. H.; Da, C. S.; Wang, H. S.; Su, W.; Wang, R.; Chan, A. S. C. J. Org. Chem. 2000, 65, 295. 